\title{
SOBRE LA PERCEPCIÓN Y LA DECISIÓN POLÍTICAS DE APLICAR EL ASILO DIPLOMÁTICO: UNA REFLEXIÓN DESDE EXPERIENCIAS LATINOAMERICANAS
}

\author{
Silvia Dutrénit Bielous*
}

Transcurridos 25 años del golpe de estado en Chile y algo menos del argentino, aparecen formas de abordar lo ocurrido que indican, desde distintas disciplinas, el interés por reflexionar sobre los hechos y por encontrar explicaciones a muchas consecuencias de esos años que hoy, todavía, marcan el futuro del subcontinente. En muchos casos la recurrencia desde el presente a los años rupturales es un llamado a la necesidad de una memoria colectiva, a que el dolor individual y societal no oculte lo que se guarda como drama y que puede tener fuerza raigal, fundacional, en los estados de este fin de siglo.

Con un enfoque de historia política, en el artículo se proponen hipótesis sobre la relación entre percepción y decisión políticas cuando se está ante el desafío de poner en práctica un instrumento del derecho interamericano: el asilo diplomático. La combinación de valoraciones políticas de los diplomáticos, de estrategias estatales de los estados involucrados y de determinaciones de los perseguidos políticos crearon situaciones muy distintas en la América Latina reciente. En las páginas que siguen se rastrean, de modo ilustrativo, experiencias de los años setenta que toman México como estado que otorga asilo, y Argentina y Chile como estados que generan perseguidos políticos, y se reflexiona sobre circunstancias aparentemente similares pero que engendraron resultados diferentes. Aquí interesa especialmente avanzar en condicionantes ajenos a la regulación interamericana del derecho de asilo pero que son sustantivos para comprender la puesta en práctica de ese derecho: ellos son la percepción y la decisión políticas. Para ello se estructura el artículo en cinco apartados: el primero, ofrece algunos datos básicos para ubicar rápidamente el tema; el segundo, centra al asilo en el tiempo y precisa la relevancia que ha tenido en América Latina y en México de manera especial; el tercero, fija las principales características de las experiencias de asilo diplomático mexicano en Argentina y Chile; el cuarto, desarrolla hipótesis sobre cómo las percepciones diplomáticas, como también la de los perseguidos, condicionan las decisiones de otorgar asilo basándose en un enfoque comparado entre lo sucedido en Argentina y Chile y, a la vez, en dos momentos históricos, en el ayer de las coyunturas críticas y en el hoy de la reconstrucción y de la reflexión; por último, el quinto, recupera algunos puntos significativos para seguir reflexionando sobre el tema.

\section{INTRODUCCIÓN}

"...considero situación de la mayor gravedad tomando en cuenta se acentúa división de las Fuerzas Armadas simultáneamente nuevo intento Congreso planteando quebrantamiento orden legal y constitucional preparando clima para posible golpe de Estado. Estímase unidades Fuerza Aérea Santiago grupo 7 al 10, Escuela Mantenimiento Especialidades y Escuela Aviación estarían contra Gobierno. Armada su mayor parte estarían también contra Gobierno. Acerca ejército' se carece datos precisos posición asumiría caso rompimiento..." 2 .

Este era el anuncio sobre la totalización de la crisis política chilena que, a través de un telegrama cifrado, urgente y confidencial ${ }^{3}$, el embajador mexicano Gonzalo Martínez Corbalá transmitía a su Cancillería.

A las dos semanas de su transmisión, el 11 de septiembre de 1973, un golpe de estado deponía al presidente constitucional Salvador Allende. Desde sus inicios, el nuevo régimen se caracterizó por desplegar una amplia y diversificada represión en contra de los funcionarios, militantes y todo aquel partidario del gobierno socialista de la Unidad Popular.

Historiadora uruguaya. Doctora en Estudios Latinoamericanos Investigadora y profesora titular del Instituto de Investigaciones Dr. José María Luis Mora, México D.F.

1. El subrayado es de la autora. Como se recordará, el mando estaba a cargo del General Pinochet.

2. Archivo Histórico Diplomático de Relaciones Exteriores Mexicanas (AHDREM), Exp. III-3215-1. Traducción de telegrama cifrado urgente confidencial de Embamex Chile a Secretaría de Relaciones Exteriores de México (SRE). Santiago de Chile, 23 de agosto de 1973.

3. Se trata del único documento con estas características que se integra en el rubro Informes politicos suplementarios de Embamex Chile y que se encuentra en el $A H D R E M$. 
La tragedia del suceso tiene su representación gráfica en el bombardeo a La Moneda y en el último discurso que pronunciara Allende ${ }^{4}$. De inmediato el nuevo régimen gravó su gestión con el asesinato, la desaparición, la prisión, la tortura física y la persecución de miles de personas. De manera contundente, abierta, sin ocultamiento de los métodos utilizados contra la oposición, la Junta Militar chilena evidenció desde el primer momento la tónica de cómo pretendía revertir la vía chilena al socialismo.

El actual juicio a Augusto Pinochet en España es significativo de las acusaciones sobre la violación a los derechos humanos acaecida durante su gestión gubernamental al igual que de su personal responsabilidad. No obstante esta aceptación bastante generalizada en distintos ámbitos gubernamentales y sociales, las tensiones generadas y las situaciones creadas a partir de su arresto ilustran sobre el difícil equilibrio de fuerzas que el propio Allende había tenido que enfrentar.

En aquellas circunstancias de ruptura de la institucionalidad, uno de los caminos por los que optó un número considerable de perseguidos políticos fue el del asilo en diversas misiones diplomáticas acreditadas en el país. Situación que fue posible por la disposición de algunos estados a concederlo y, en particular, por la protección que el estado mexicano dio, a través de su embajada en Santiago de Chile, a centenares de perseguidos 5 .

Y años después otro diplomático mexicano, el embajador en Argentina Roque González Salazar, transmitía a su cancillería una nueva coyuntura de ruptura institucional en América Latina.

"La toma del poder por las fuerzas armadas la madrugada del 24 de marzo de 1976 no fue una sorpresa casi para nadie. Lo asombroso quizás estuvo en que no hubiera ocurrido antes y en que el gobierno de la señora Perón hubiera logrado mantenerse por tanto tiempo en el poder ... A manera de conclusiones, Señor Secretario, a continuación gloso los principales puntos de esta carta, que pretende reflejar mi opinión personal sobre la situación actual de Argentina: a) El gobierno de la Junta Militar presidido por el General Videla es una dictadura de derecha. Hasta la fecha ha actuado con moderación en la represión. No debe descartarse, sin embargo, la posibilidad de que, con el pretexto de acabar con la ola de violencia que ha aumentado últimamente tanto de la derecha como de la izquierda, el gobierno militar endurezca su posición frente a quienes podría considerar como sus opositores, que se reclutarían principalmente en las filas de la izquierda política y en el sindicalismo, pero también entre militantes más moderados del centroizquierda y del centro. b) El nuevo gobierno ejerce control absoluto de la situación y lo seguirá ejerciendo por un tiempo indeterminado y probablemente largo. La vuelta a una vida constitucional no se avizora en el futuro previsible. c) El sistema económico establecido es del más puro liberalismo" ${ }^{\circ}$.

En este primer informe, posterior al derrocamiento del gobierno peronista, el diplomático expone sus impresiones de lo que consideraba una situación anunciada desde mucho tiempo atrás. Sin duda, el segundo peronismo, de la vuelta de exilio, con Perón y luego sin él, condujo a una violenta confrontación dentro de las propias filas del justicialismo y a una creciente situación de ingobernabilidad con tintes de guerra civil. El involucramiento creciente de grupos paramilitares amparados desde el gobierno de María Estela Martínez de Perón y la acción armada de distintos grupos de la izquierda radical evidentemente generaron mucho antes del golpe de estado un escenario de extrema violencia. Claro está que la violencia no disminuyó con la irrupción de las Fuerzas Armadas. Por el contrario, la recurrencia actual a romper el silencio, y a dar a conocer las distintas formas utilizadas para el extermino de la oposición, exhiben dramáticamente lo sucedido. Y también, en el sentido de contribuir a evidenciar lo ocurrido, está la práctica que busca presentar ante los tribunales a los principales responsables de los delitos cometidos, sorteando las trabas impuestas por las leyes de obediencia debida y de punto final, y por la amnistía que decretó Menem.

Pero en todo caso, lo que dejó de existir con el régimen militar fue el escenario de violencia en donde había un relativo empate entre las fuerzas confrontadas. De manera sostenida, y con una estrategia de exterminio, las Fuerzas Armadas fueron aniquilando a sus "enemigos". Y fue en ese contexto de violencia, previo al golpe de estado y después de su ejecución, que también algunos de los perseguidos políticos argentinos buscaron la protección diplomática mexicana. Ello se dio en número considerablemente menor que en el caso chileno, distando mucho de alcanzar el centenar ${ }^{7}$.

4. "Trabajadores de mi patria: tengo fe en Chile y en su destino. Otros bombres superarán este momento gris y amargo donde pretende imponerse la traición. Sigan ustedes sabiendo que, mucho más temprano que tarde, se abrirán las grandes alamedas por donde pase el hombre libre para construir una sociedad mejor".

5. Por estas circunstancias la representación diplomática recibió la siguiente nota del Gral. de Carabineros (R) Aníbal Alvear Godoy al Embajador de México en Chile: “...es que me permito molestar su atención, para manifestarle mi pesar por las noticias contradictorias y desinformadas, publicaciones bechas en la prensa azteca, sobre los acontecimientos que ba vivido nuestro país últimamente, para reconquistar su libertad y su democracia... seguramente se deben a una campaña orquestada por los enemigos de Chile, dirigida por los mismos que llevaron al pais a la caótica situación politica y social que de no mediar la intervención de nuestras Fuerzas Armadas y de Carabineros habriamos desaparecido como nación digna y soberana. Es de suponer lo que habria ocurrido, en nuestro país, señor Embajador, si se bubieran cumplido en su integridad los planes para entronizar una dictadura del proletariado por medio del terror, la violencia y el despojo, de acuerdo a la documentación encontrada en poder de los jerarcas del marxismo criollo... En consecuencia, carece de verosimilitud lo publicado por alguna prensa mexicana y extranjera, interesada en distorsionar la verdad de los bechos ocurridos en Chile. Sin embargo, poco o nada se ha publicado sobre el engaño que fue victima el pueblo chileno por los cobardes dirigentes marxistas, quienes atiborrados de dinero nacional y extranjero, fueron los primeros en buir o refugiarse en embajadas extranjeras para eludir la responsabilidad de las acciones delictivas...si lo tiene a bien, me permito solicitarle se sirva dar a conocer a los medios informativos del noble país azteca la realidad chilena actual, en atención que nuestro país intenta salir del caos, para vivir una nueva era de trabajo y paz'. AHDREM, Exp. III-3215-1. Información de prensa "El Mercurio” de Embamex a SRE. Santiago de Chile, 25 de octubre de 1973.

6. AHDREM, Exp. Archivo de la Embajada Mexicana en Argentina (AEMARG) LEG. 91, Exp. 9. Informe de Embamex Argentina a SRE. Buenos Aires, 5 de abril de 1976.

7. El número menor de perseguidos políticos que amparó la embajada mexicana en Buenos Aires no evitó la serie de amenazas que recibió el embajador Roque González Salazar y la propia representación diplomática. 


\section{LA INSTITUCIÓN DEL ASILO EN AMÉRICA LATINA}

Hay que recordar que el término asilo, en un sentido muy amplio, designa una singular forma de protección de la que puede gozar un individuo al estar dentro de un espacio delimitado e inviolable tanto por atributos de sacralidad o por condiciones de extraterritorialidad como en virtud de prerrogativas de inmunidad ante los órganos de la justicia local ${ }^{\text {. }}$.

La historia del asilo pone de manifiesto que la institución ha atravesado por distintas etapas y diferentes contenidos que son factibles de presentarse sintéticamente así. Una primera clasificación distingue entre asilo religioso (o eclesiástico) y asilo diplomático. El eclesiástico es el más antiguo y fue conferido como forma de protección a los perseguidos por delitos del orden común. Su práctica se basó en las creencias religiosas de las comunidades al reconocer el carácter sacro de ciertos espacios que tenían el privilegio de estar protegidos por los dioses, siendo por tanto inviolables. La jurisdicción del asilo religioso comenzó en el siglo IV de nuestra era. El asilo diplomático hace su aparición al quedar atrás el medioevo, cuando se afirma el poder del estado civil y su soberanía, y cuando empieza a ejercerse el monopolio estatal en el campo de la represión. Para su concreción fue necesario el reconocimiento de las primeras formas de representación diplomática con carácter de permanentes, lo que sucedió recién en el siglo XV. Hasta ese entonces, las técnicas diplomáticas y las propias embajadas habían tenido un carácter de eventualidad y de limitada temporalidad".

Una segunda clasificación muestra al asilo como institución para la protección de los perseguidos del orden común y para la protección de los perseguidos políticos. Tanto el asilo eclesiástico como el diplomático tuvieron el fin de proteger a los delincuentes del orden común. Pasada la revolución francesa, que imprimió una transformación en la historia de los derechos del hombre y del ciudadano, el asilo diplomático fue concebido como institución para proteger a los perseguidos políticos. Pero la secularización efectiva, y la fuerza que en ella tomó el asilo como institución que debía resguardar y proteger a los perseguidos políticos, se originó durante el siglo XIX y se consolidó finalmente en el siglo XX.

Una tercera clasificación distingue entre asilo territorial y asilo diplomático. El asilo diplomático es el que ofrece un estado en territorio extranjero, amparado en la prerrogativa del principio de la extraterritorialidad. Por lo general, se brinda en las misiones diplomáticas aunque podría llegar a aplicarse a bordo de naves, en bases militares y hasta en lugares que las propias misiones diplomáticas dispongan, y debidamente informen, para que se ejerza la prerrogativa de extraterritorialidad. Contrariamente al asilo diplomático, el

Cuadro 1. Clasificación de tipos de asilo

\begin{tabular}{|l|l|l|l|}
\hline $\begin{array}{l}\text { Clase de } \\
\text { perseguido }\end{array}$ & \multicolumn{3}{|l|}{ Clase de institución } \\
\hline $\begin{array}{l}\text { Perseguidos del } \\
\text { derecho común }\end{array}$ & & Religiosia & Diplomática \\
\hline $\begin{array}{l}\text { Perseguidos } \\
\text { políticos }\end{array}$ & Ámbito & & \\
\hline & Territorial & & \\
\hline & Extraterritorial & & Casos cstudiados en este artículo \\
\hline
\end{tabular}

asilo territorial es la concesión de protección de un estado en su propio territorio a un individuo proveniente de otro estado. La historia registra desde el siglo XVII al asilo territorial como instituto jurídico.

En América Latina el asilo ha estado incorporado en la agenda de los estados ocupando la atención y el trabajo tanto de juristas como de gobernantes. La conflictiva vida política de la región ha tenido un peso decisivo en la ininterrumpida tarea por precisar la regulación del asilo y por afirmar su carácter sustancialmente político. El inicio de la experiencia en términos de regulación acordada y de creación de instrumentos convencionales interamericanos se plasma en el Tratado Montevideo de 1889 y tiene, como último momento significativo, la Convención de Caracas de 1954. Cuatro convenciones ${ }^{10}$, La Habana (1928), Montevideo (1933 y 1939) y Caracas (1954) ", y distintas reuniones interamericanas, ejemplifican la labor realizada mientras el volver reiteradamente sobre el tema deja ver que sigue presente la necesidad de continuar trabajando en la regulación. ¿Por qué? Porque a pesar de estos avances, la experiencia de las últimas décadas permite afirmar que aún quedan muchos vacíos en los ordenamientos convenidos entre los estados.

Cuadro 2. Hitos principales del derecho interamericano de asilo en el siglo $\mathrm{XX}$

\begin{tabular}{|l|l|l|}
\hline Clase de acuerdo & Lugar & Año \\
\hline $\begin{array}{l}\text { Convención sobre el Asilo político de las VI y VII Conferencias } \\
\text { Panamericanas }\end{array}$ & $\begin{array}{l}\text { Habana } \\
\text { Montevideo }\end{array}$ & $\begin{array}{l}1928 \\
1933\end{array}$ \\
\hline $\begin{array}{l}\text { Tratado sobre Refugio y Asilo político del II Congreso } \\
\text { Sudamericano de Derecho Internacional }\end{array}$ & Montevideo & 1939 \\
\hline $\begin{array}{l}\text { Convención sobre el derecho de asilo de la X Conferencia } \\
\text { Internacional de los estados americanos }\end{array}$ & Caracas & 1954 \\
\hline
\end{tabular}

México ha participado desde los inicios de la implantación del asilo diplomático en América Latina. Su historia guarda los momentos constitutivos del asilo cuando, en la tercera década del siglo XIX, se efectuó un acuerdo pionero con Colombia. Su relevancia fue cada vez mayor; primero se transformó en artículo de la constitución de 1857 y más adelante de la constitución de $1917^{12}$. Quedó establecido así el derecho constitucional de asilo político ${ }^{13}$. Al mismo tiempo

8. Véase un estudio exhaustivo en Francesco Francioni, Asilo diplomatico. Contributo allo studio delle consuetudini locali nel diritto internazionale, Milano, Giuffrè Editore, 1973

9. "Già nel 1593 si nota in Francia uno dei primi esempi di conflitto fra potere civile e potere ecclesiastico in materia d'asilo con l'emanazione dell'ordinanza di Villers-Cotterettes di Francesco I, la quale aboli l'immunità degli edifici del culto ai fini della concessione dell'asilo religioso", ibid. p. 3.

10. Aspectos relevantes de las cuatro: Habana (1928) definió que el asilo sólo era válido para los perseguidos políticos; Montevideo (1933) estableció que es el estado asilante es el que califica el delito como político; Montevideo (1939) distinguió entre asilo diplomático y asilo territorial entre asilo y refugio, y Caracas (1954) precisó la distinción y avanzó notoriamente en la regulación.

11. Inter-American Treatises and Conventions, Signatures, Ratifications and Deposits with Explanatory Notes, Washington, 1971.

12. Felipe Tena Ramírez, Las leyes fundamentales de México 1808 1957, México, Porrúa, 1957, pp. 608 y 822.

13. El Servicio Exterior de México asume, para calificar a los asilados, la definición de delito político que se encuentra en el Código Penal para el Distrito y Territorios Federales de 1931, vigente en la actualidad aunque con numerosas reformas. En el artículo 144 se establece que: "Se consideran delitos de carácter político los de rebelión, sedición, motín y el de conspiración para cometerlos". Véase Francisco González de la Vega, El Código Penal comentado. Precedido de la reforma de las leyes penales en México, México, Porrúa, 1978, pp. 45-46. 
se constituyó en práctica como lo registran distintos momentos de la historia del siglo. El derecho de asilo es un precepto de la política exterior mexicana y se le reconoce desde hace más de un siglo. Una rápida revisión evidencia coyunturas significativas como las relacionadas con: León Trotsky en los años treinta, pasando por aquella en la que se asiló el importante contingente de republicanos españoles en los mismos años treinta, continuando por las signadas por la permanente recepción de centroamericanos y caribeños (cubanos, hai tianos y dominicanos) hasta llegar a la que registra el ingreso a México del considerable grupo de conosureños de los años setenta ${ }^{14}$.

La jerarquización que el asilo ha tenido en la política exterior está vinculada también a los principios fundamentales plasmados esencialmente en las doctrinas Carranza y Estrada y, además, en una serie de instrucciones emanadas de la cancillería mexicana que pretendieron ubicar correctamente los principios y la voluntad del estado mexicano y facilitar así la labor de los diplomáticos. Ello no significa que estas directrices generales y específicas no permitían un margen de acción para quienes tenían la representación de México en el exterior. Y estas posibilidades de actuación diplomática se entrecruzaron con intereses y estrategias de los distintos gobiernos mexicanos que muchas veces fueron independientes de la disposición constitucional de otorgar el derecho de asilo a los perseguidos políticos.

Actuaciones individuales de los diplomáticos, intereses y estrategias gubernamentales, que trascienden la política exterior del estado mexicano, caen muchas veces en los vacíos de la regulación sobre asilo diplomático que se ha establecido en el derecho interamericano. En un estudio reciente basado en algunas experiencias de los años setenta se concluye que es necesario continuar examinando teoría y aplicación del asilo diplomático en América Latina, tanto en lo que respecta a las relaciones internacionales como en relación con la búsqueda de un mayor acercamiento entre la esencia filosófica del derecho y su aplicación ${ }^{15}$.

\section{DE LOS GOLPES DE ESTADO Y EL ASILO DIPLOMÁTICO EN ARGENTINA Y CHILE}

Ante la resolución de las crisis políticas mediante golpes de estado militares en Chile (septiembre de 1973) y en Argentina (marzo de 1976) en lo inmediato se generó en los perseguidos políticos la necesidad de encontrar un resguardo, un refugio. Muchos en el caso chileno, pocos en el caso argentino, decidieron lograrlo solicitando asilo en la misión diplomática mexicana. Se trata pues de un mismo estado asilante que había retroalimentado durante el siglo $\mathrm{XX}$ una disposición a la protección de los perseguidos políticos de diferentes nacionalidades. Eran al mismo tiempo años históricamente cercanos, 1973 y 1976, y dentro de un mismo sexenio político mexicano, el del presidente Luis Echeverría Alvarez.

El 11 de septiembre de 1973 se produce el golpe de estado en Chile y al día siguiente la embajada de México en Santiago comienza a recibir solicitudes. En pocas horas, la residencia de Martínez Corbalá y la cancillería se convierten en refugios saturados de gente. Una política de puertas abiertas a quienes solicitaran protección, con una disposición a socorrer a figuras públicas del gobierno socialista que requerían amparo, fue la principal característica de la gestión de Martínez Corbalá ${ }^{16}$. Así fue como, por ejemplo, recibieron asilo diplomático la familia del presidente Allende al mismo tiempo que Pedro Vuscovic, Luis Maira y Jaime Fainvovich. Y desde el hospital en que se encontraba internado, Pablo Neruda ya había aceptado, a sugerencia de Martínez Corbalá, trasladarse a México con protección gubernamental pero sin ostentar la calidad de asilado.

Según fuentes diplomáticas más de 800 personas fueron calificadas como asilados. Y se ha llegado a referir la cifra de $2000^{17}$, seguramente considerando personas que recibieron el refugio diplomático aun cuando no se les calificó como asilados. La coyuntura de mayor demanda fue durante los días inmediatos al golpe de estado, cuando ingresaron alrededor de 500 personas. El grupo se conformó por altos funcionarios del gobierno derrocado, dirigentes partidarios, militantes políticos, algunos miembros de las Fuerzas Armadas y de seguridad. También recibieron protección diplomática ciudadanos de otras nacionalidades que corrían el riesgo o eran pasibles de convertirse en víctimas del nuevo régimen ${ }^{18}$. Sobre esta última mención, hay que recordar que en los primeros setenta, ante la propuesta de la vía chilena al socialismo, corrió un aire de ilusión transformadora en la región. Por eso en Chile se reunieron hombres y mujeres que representaban distintos movimientos y grupos de la izquierda latinoamericana.

Pero si bien el primer objetivo del asilo diplomático, la protección al perseguido, era un hecho para aquellos que habían logrado de diferentes maneras pasar los muros hasta penetrar en el interior mismo de la misión diplomática, no era una situación totalmente suficiente como para abandonar el país. Se requería obtener el documento oficial, el salvoconducto que, según establece la regulación interamericana sobre asilo diplomático, debe ser expedido por el estado territorial (en este caso Chile) y entregado al representante del estado asilante (en este caso México). Sobre este aspecto no existe en los preceptos del instrumento jurídico emanado de la Convención de Caracas una especificación de cuán-

14. A manera de ejemplo se anotan algunas de los casos que están registrados: Luis Buñuel, José Gaos, Nicolás Guillén, Pablo Neruda, Víctor Haya de la Torre, Luis Cardoza y Aragón, Rigoberta Menchú, Hortencia Bussi de Allende y Héctor Cámpora. Confróntese Cecilia Imaz, La práctica del asilo y del refugio en México, México, Potrerillos Editores S.A. de C.V., 1995. p. 47

15. Sus resultados aparecen en: Silvia Dutrénit y Guadalupe Rodríguez (coords.), El asilo diplomático mexicano en el Cono Sur, México, Instituto Mora/SRE, 1999 y Ana Buriano (ed.), Silvia Duténit y Guadalupe Rodríguez, Tras la memoria: experiencias de asilo en las embajadas mexicanas del Cono Sur, México, Instituto Mora (en prensa).

16. Apoyado en Gonzalo Martínez Corbalá, Instantes de decisión. Chile 1972-1973, México, Grijalbo, 1998. p. 206 y en Entrevista realizada a Gonzalo Martínez Corbalá por Silvia Dutrénit en México, D.F., el 11 de diciembre de 1996.

17. Ibid.

18. La referencia es a personas de otra nacionalidad (no chilena) con las que se creó una situación que podría considerarse de irregular pero que México la sostuvo en acuerdo con la calificación de perseguido político. AHDREM, Exp. III-6018-1 (5a. parte). Nota mecanuscrita "Posición de México en materia de asilo. México concede asilo con base a las Convenciones de La Habana, Montevideo y Caracas", s.p.i 
to tiempo puede tomarse el estado territorial para emitirlo. Es decir, se declara que "Otorgado el asilo, el Estado asilan. te puede pedir la salida del asilado para territorio extranjero, y el Estado territorial está obligado a dar inmediatamente, salvo caso de fuerza mayor, las garantías necesarias a que se refiere el Artículo V y el correspondiente salvoconducto" ${ }^{\prime 9}$, dejando ver la intención de regular eficazmente también en el sentido de que se permita evacuar con rapidez a los asilados evitando convertir las misiones diplomáticas en refugios eternos, en lugares de confinamiento, a veces de hacinamiento. Sin embargo, el salvoconducto se vuelve un instrumento de tensión y negociación en la relación entre los estados, presentándose una variedad de comportamientos en una misma experiencia nacional.

En Chile fue posible disponer de la mayoría de los salvoconductos en tiempos razonables, en días o semanas y hasta en un poco más de un mes. Alrededor de 500 casos, entre ellos los de la familia Allende, fueron resultado de la negociación directa del embajador Gonzalo Martínez Corbalá. Aunque sí hubo 71 casos difíciles de resolver, los denominados "peces gordos" por la Junta Militar; para los que el trámite tardó 8 meses, y necesitó de una negociación especial, un acuerdo específico con el gobierno mexicano. En esta última negociación estuvo directamente involucrado el canciller Emilio Rabasa. Y fue el mismo canciller quien acompañó el vuelo en el que se transportaba a los últimos asilados de Santiago a México. Esto ocurría en junio de 1974 y, en noviembre, México declaró la ruptura de relaciones con Chile. Las relaciones se reanudaron con el gobierno de Patricio Aylwin.

El 24 de marzo de 1976 era derrocado por un golpe militar el gobierno de María Estela Martínez de Perón. Algunas horas antes, en la cancillería mexicana en Buenos Aires, se presentaron 26 personas de un mismo núcleo familiar que solicitaban asilo diplomático. Se trataba de la familia cordobesa Vaca Narvaja que en ese momento tenía a uno de los hermanos requerido, Fernando, dirigente montonero, a otro detenido, Hugo, defensor cle presos políticos (quien fuera asesinado unos meses después) y al padre, abogado y exministro del gobierno de Frondizi, desaparecido. La demanda de asilo por parte de la numerosa familia no fue un trámite sencillo, debieron pasar horas de alegatos, réplicas y tensión con los funcionarios mexicanos hasta que el embajador giró instrucciones a sus subordinados para que fuera aceptada la solicitud ${ }^{20}$.

Cuadro 3. Principales caracteristicas de la aplicación de la política de asilo mexicana

\begin{tabular}{|l|l|l|l|}
\hline Paises & Nomento de la solicitud & Nümero de asilados* & $\begin{array}{l}\text { Periodo máximo de } \\
\text { permanencia en las } \\
\text { embajadas }\end{array}$ \\
\hline Argentina & $\begin{array}{l}\text { Antes y después del golpe de } \\
\text { estado (24-3-76) }\end{array}$ & 65 & Mas de 6 años \\
\hline Chile & Después del golpe (11-9-73) & 800 & Mas de 8 meses \\
\hline
\end{tabular}

Fiuenle: claboración de la autora basada en los documentos diplomáticos del $A H I$ SSRLM

* Números aprosimados a partir de la documentación de las personas califícadas como casilectos politicos

La situación de la familia Vaca Narvaja es representativa del tipo de represión que desató la Junta Militar; y desde antes, ya se había comenzado a vivir en Argentina. De ahí la mención específica, por ilustrativa y porque puede servir como referencia para una comparación del caso nacional con otros. Lo cierto es que en las semanas subsecuentes no mucho más de una veintena de casos fueron confirmados como asilados por la embajada mexicana en Buenos Aires. De ellos solo tres se presentaron directamente en la residencia, eran el expresidente peronista Héctor Cámpora y su hijo, con el mismo nombre, y el exsecretario general del Partido Justicialista, Juan Manuel Abal Medina. Aparentemente en estos tres casos no se requirió mayor trámite; lo que sí se les requirió fue llegar por sus propios medios a la residencia. Otros veinte perseguidos políticos fueron reconocidos como tales y aceptados por la misión diplomática antes del golpe de estado. Esto último es sin duda una peculiaridad de la experiencia argentina y guarda relación con la propia conflictividad política y la represión que se gestaron en los años 74-75. Marca también la peculiaridad y los puntos de tensión en la práctica de asilo al establecer la necesidad de otorgar protección durante el ejercicio de un gobierno elegido democráticamente y con el que se mantenían cordiales relaciones de estado ${ }^{21}$.

El número de asilados en Argentina fue notoriamente más pequeño, una cifra estimada a partir de los documentos diplomáticos arroja la cantidad de 65, y con tiempos de ingreso distintos que no obligó, además, a utilizar más que la residencia del embajador como lugar de refugio. De tal forma que la peculiaridad en este caso no fue el hacinamiento,

19. Tratados ratificados y convenios celebrados por México, México, Senado de la República, 1972. Tomo XIII. p. 357.

20. La solicitud se hizo directamente presentándose a la Cancillería y sosteniendo de manera enérgica que no saldrían de ahí. La carta en la que piden el asilo dice: "Tenemos el agrado de dirigirnos a usted a los fines de solicitar asilo político para el grupo familiar que abajo se detalla Fundamentamos la misma por los hechos que son de público conocimiento que resumimos en los siguientes puntos: 1) Secuestro y desaparición de nues tro padre Miguel Hugo Vaca Narvaja del cual no bemos tenido información desde el dia 9 de marzo del corriente año. 2) Detención de nuestro bermano mayor Miguel Hugo Vaca Narvaja desde el 22 de noviembre y a disposición del poder ejecutivo sin que se le haya tomado declaración alguna y sin antecedentes politicos salvo de ser apoderado del Partido Auténtico. 3) Falta de garantia al nicleo familiar que está siendo sometido a una premeditada acción psicológica con amenazas tanto a su integridad física como asi también de sus hijos. Ante esta situación no tenemos otro camino que el asilo politico ya que no tenemos garantias para la tramitación de documentos como asi tampoco la de permanecer en nuestros domicilios habituales. Solicitamos de esta forma se nos conceda el asilo a la brevedad". AHDREM, AEMARG, Leg. 91 Exp.

9. Carta mecanuscrita de la Familia Vaca Narvaja a Embamex Argentina. Buenos Aires, 22 de marzo de 1976.

21. "Entonces mucho antes del golpe y mucho antes de que se presentara una situación politicamente, abiertamente bostil a los intelectuales, la Embajada de México, actuaba un poco como intermediaria, yo tenia por otra parte, contactos, muy buenos contactos aqui también por mis antecedentes académicos con la Asociación Nacional de Universidades, con los directivos de esa asociación, con otras universidades, con los rectores y sabia con alguna precisión de que carencias... en dónde acomodaria mejor un intelectual argentino que estaba en problemas sin que se hiciera una concentracion y sin darle demasiada importancia, digamos politica, a ese hecho. El presidente Echeverria cstaba informado de eso por mi y no sólo lo aprobaba sino que lo estimulaba pero como no se trataba de asuntos de oficial. oficialmente de asilo, yo no tenia que informarlo ni a la Secretaria de Relaciones Exteriores ni a nadie, simplemente bacer las gestiones a mi leal saber y entender recomendando directamente a los rectores en las universidades un determinado intelectual. A veces lo único que forzábamos un poco, cuando ellos no podían, los intelectuales, obtener su pasaporte, por el riesgo que corrian o porque se los negaban o por... permitir la salida un poco subrepticiamente, o más bien la llegada, es que salieran como pudieran, generalmente salian via Brasil, los que no tenian pasaporte, pero yo me encargaba de que bubiera quien los recibiera aqui en el aeropuerto y les regularizara esa situación irregular, pero no era, repito, oficialmente casos de asilo". Entrevista realizada a Roque González Salazar por Silvia Dutrénit Bielous en México, D.F., el 14 de mayo de 1998. 
sino el tiempo de permanencia de los asilados en la misión diplomática. El trámite de los salvoconductos en Argentina impuso una característica notoriamente diferente a otras experiencias, no sólo respecto a la chilena.

Existieron primero algunas dificultades con el gobierno de la Sra. Perón por la percepción mexicana de que había perseguidos políticos que requerían de la protección diplomática. Ello despertó una reacción negativa a la expedición de salvoconductos, devino entonces una práctica de "protección" que no pasó por la reglamentaria calificación de asilado de varios de los solicitantes. Después del golpe de estado fueron expedidos sin mayor problema la mayoría de los salvoconductos pero quedaron tres casos que marcan la especificidad de la experiencia. Esta segunda instancia fue mucho más compleja: los salvoconductos de Cámpora, padre e hijo, y de Abal Medina se convirtieron en punto de fricción en la relación entre los estados, exhibiendo un desplegado juego de estrategias tanto en la política interna como en la internacional. La irresolución del problema alcanzó una permanencia histórica para el asilo diplomático: 6 años vivió Abal Medina, tres años el expresidente peronista, y unos meses más su hijo ${ }^{22}$, en la residencia diplomática hasta que les fue posible viajar a México. Varios embajadores, otros tantos encargados de misión y más de un canciller forman parte de una negociación que llegó al extremo de que Abal Medina estuviera dentro de la embajada mexicana en Buenos Aires durante casi toda la dictadura.

\section{SIMILITUDES Y DIVERGENCIAS DE LAS EX- PERIENCIAS DE ASILO: ALGUNAS HIPÓTESIS}

Es pues el asilo diplomático relevante como expresión de uno de los nichos de las relaciones que establecen los estados en situaciones de conflicto. Es relevante también porque, respondiendo a un imperativo que emanó de la historia del siglo XIX latinoamericano y que fue ratificada con mayor fuerza en la del XX, expresa la configuración de un instrumento de protección reconocido y regulado en el derecho interamericano. La experiencia mexicana de los años setenta en Argentina y Chile es ilustrativa no sólo de los puntos de tensión en la regulación del asilo diplomático sino también de los nudos problemáticos que presenta. ¿Por qué? Porque entre las similitudes que fácilmente se pueden apreciar, en términos del mismo estado que otorga el asilo, durante la gestión de un mismo presidente y en situaciones de regímenes militares con rasgos fuertemente coincidentes, las experiencias son escasamente equiparables en la aplicación del asilo tanto por parte de los embajadores como por la valoración de su posibilidad real por parte de los perseguidos.

Interesa para el argumento que se está siguiendo recuperar especialmente las perspectivas diplomáticas y estatales, y considerar por su importancia la de los perseguidos políticos, como factores coadyuvantes en las particularidades de los casos nacionales. En tal sentido se sostienen tres hipótesis centrales apoyados en la evidencia de las propias percepciones que los protagonistas tenían entonces y tienen hoy ${ }^{23}$.

¿Cuáles podrían ser los principales aspectos que juegan en las diferentes determinaciones nacionales?
Una primera hipótesis tiene que ver con las relaciones entre el gobierno mexicano (estado asilante) y los gobiernos y las fuerzas políticas que fueron derrotadas en Chile y Argentina (estados territoriales) además de contra quienes se dio finalmente el golpe de estado. La muy cercana relación entre los gobiernos de Luis Echeverría Alvarez y de Salvador Allende despertó en el ejecutivo mexicano la inmediata disposición a dar refugio al gobierno derrocado y a los militantes de la Unidad Popular. Identificando claramente a los perseguidos políticos con miembros del gobierno o militantes allendistas que formaban parte de distintos niveles de las estructuras político partidarias. La situación no es la misma cuando el gobierno peronista fue derrocado por la Junta Militar. Aunque el presidente Echeverría manifestó en su momento la disposición a aplicar la política de asilo ante el eventual golpe de estado, comparativamente ni su relación con el gobierno constitucional argentino había sido tan estrecha, ni la mayoría de los perseguidos formaban parte del gobierno. Un menor compromiso con el gobierno derrocado y al mismo tiempo un golpe de estado que iba más allá de desplazar al peronismo gubernamental, es decir, los perseguidos políticos eran al mismo tiempo quienes se habían opuesto al gobierno de la Sra. Perón. La fuerza de la relación planteada jerarquiza esta variable en la decisión de otorgar el asilo y hace esfumar el peso de otras que no deben descartarse en la decisión de su aplicación. La referencia de otras es, por un lado, a la variable "momento del sexenio", en tanto un golpe fue en el 73 y otro en el 76, ocurriendo este último sobre el final de la gestión de Echeverría Alvarez, y por el otro, a la variable "estrategia del presidente" que contempla la factible intervención de aspectos sustantivos de política interna del ejecutivo (en este caso mexicano) ${ }^{24} \mathrm{en}$ cuanto a promover o cerrar la política de asilo.

22. El salvoconducto para Héctor Cámpora se obtuvo cuando la Junta Militar pudo comprobar con sus propios médicos que el expresidente tenía un cáncer muy avanzado que él mismo ya se había diagnosticado. El salvoconducto de su hijo fue expedido al ser comunicada la muerte de su padre.

23. La configuración de estas percepciones así como la reconstrucción de las decisiones están basadas en la documentación diplomática corres pondiente a la comunicación generada con la Cancillería que se guarda en el $A H D S R E M$, en apuntes diplomáticos personales y en los testimonios que fueron recogidos en los últimos años para el Proyecto Asilo y dictaduras del Instituto Mora de México, D.F.

24. Es ilustrativo en este caso, e interesante a considerar en los estudios sobre política interna y aplicación del asilo, la siguiente afirmación de embajador González Salazar: "Bueno, solamente esas dos, esos dos puntos subrayó el presidente Echeverria en sus instrucciones. Primero con relación al asilo, a las posibilidades de asilo, que tenia que estar muy, muy generoso y muy abierto a todas estas posibilidades. Ya babia ocurrido, según creo, Chile verdad, lo de Chile, y bueno eran experiencias, babian sido experiencias afortunadas digamos para México desde el punto de vista de su prestigio internacional y desde el punto de vista también de los beneficios. Hay que verlo también de esa manera, reportaba para el país el acoger a personas tan bien formadas, tan distinguidas, que pudieran asimilarse aquí. Localmente se producian algunos roces, algunos problemas, por la fricción que esto genera que se sienten algunas personas desplazadas, obstaculizadas porque vienen de otra parte pero, en realidad, en el fondo, el beneficio es para el país. Sin ninguna duda está abi manifiesto, afecta algunos intereses personales inmediatos pero el beneficio es general. Pero yo creo que sobre todo, lo que mueve o lo que movia al menos en ese caso al presidente Echeverría, al darme esas instruc ciones era, sobre todo, el prestigio que daba a México el practicar una politica de ese tipo, de puertas abiertas y de generosidad para los intelectuales. Generalmente abi es donde se manifiesta a los intelectuales en condiciones de apuro, y tal vez, y eso no quisiera entrar a analizarlo porque pues no sé los 
El desarrollo específico del asilo en la embajada en Buenos Aires pone en evidencia cierta retracción más que una apertura para la concreción de la política tradicional mexicana. Seguramente entonces los antecedentes de cooperación del gobierno mexicano con el chileno en los momentos extremadamente críticos ${ }^{25}$ son muestra de una mayor condescendencia que favorecería, tiempo después, la disposición de poner todos los recursos necesarios para llevar hasta el fin exitosamente el asilo ${ }^{26}$.

Una segunda hipótesis se relaciona con la percepción que los embajadores (o encargados de las misiones diplomáticas) tienen sobre las crisis y las fuerzas confrontadas. $\mathrm{Si}$ el asilo diplomático es una regulación que debe ser conocida por los embajadores, en general su aplicación no figura en la historia personal de quienes son o fueron los miembros del servicio exterior. Y ante una situación de crisis en la que in situ es necesario decidir, el embajador está sujeto a una gran presión entre lo que advierte, lo que debe transmitir a su cancillería y la decisión última que en definitiva es suya Ahí es cuando comienza a imprimir su política que está indisolublemente ligada a su percepción de la crisis, de las fuerzas encontradas y de su valoración de la represión.

Un ejemplo está dado en estas dos formas de resolución. Por un lado, la búsqueda que de muchos de los perseguidos políticos hiciera el embajador Gonzalo Martínez Corbalá, tratando de localizarlos y yéndolos a recoger para protegerlos en la embajada. Y por el otro, en Buenos Aires, al facilitar en algunos casos el ingreso a la embajada, cuando la representación diplomática estaba a cargo del embajador Roque González Salazar, pero sin posibilitar forma alguna de protección fuera de los límites de la representación diplomática ${ }^{27}$.

Al respecto sería factible afirmar que sobre la confrontación y la crisis, tanto ayer y hoy las percepciones y decisiones fueron distintas. Y al mismo tiempo se vuelven elocuentes en la reconstrucción que desde el presente hacen los embajadores reafirmando conductas en tanto el mandato diplomático con el que estaban investidos. En este aspecto Martínez Corbalá considera hoy como ayer lo siguiente:

“...agrego que entre equivocarme y cerrar las puertas de la embajada a quien pedía protección, calificando su solicitud de innecesaria o excesiva, para que luego fuera ejecutado en el asfalto o en la banquetas -veredas, dicen los chilenos-, tal y como pasó frente a nuestra cancillería, o bien, por el contrario, ser demasiado liberal o magnánimo en el otorgamiento del asilo, preferí siempre, consciente y responsablemente, situarme del lado de la seguridad de los solicitantes y actuar en consecuencia" ${ }^{28}$.

Mientras González Salazar que sostuvo una posición más apegada a la regulación del asilo afirma desde el presente que:

"en consecuencia pues es posible que haya errores, muchos errores de apreciación y de juicio por las limitaciones de información, por las dificultades de la situación en que generalmente se dan esos casos y seguramente muchos que merecerían quizá recibir la calificación de asilado político no la reciben por un error del embajador o por una omisión en las pruebas, eso es muy posible pero es muy difícil de poder generalizar porque la norma digamos, al menos nuestras normas y nuestra práctica la mexicana establece que el peligro tiene que ser inminente de perder la vida o la libertad y eso de la inminencia pues es un elemento difícil y a veces también por la situación misma de las circunstancias políticas se crea una paranoia colectiva y mucha gente se siente perseguida más allá de lo que en realidad es perseguida y hay algunos otros que confunden también ciertos actos de hostigamiento con peligro de su seguridad personal o de su integridad personal por ejemplo el caso más frecuente son los que son asediados, hostilizados por sus ideas...Bueno pues si ese es un hostigamiento y una hostilización pero no es digamos teóricamente ninguna causa para dar asilo, no hay un peligro inminente de que se pierda la vida, muchas personas en todos los países son hostigados de esa manera también por sus enemigos políticos. Entonces si hay ese riesgo, pero yo debo decir como una confesión personal que creo que también muchos colegas míos habrán compartido que el momento más difícil que uno tiene como embajador es cuando tiene que calificar un asilo es el de decir que no porque tiene uno la duda que a lo mejor al franquear la puerta de la Embajada va a ser detenido y quizá asesinado, esa es un fantasma que aqueja a los embajadores... pero en muchos casos también uno se ve tentado y cede a esa tentación de en caso de duda mejor concederlo, mejor conceder el asilo..." ${ }^{29}$.

Una tercera hipótesis se refiere al tipo de represión específica en cada país y a la información y a la valoración de los perseguidos políticos. ¿Qué se quiere decir con esto? Al menos tres cosas. El exterminio como meta para erradicar al "enemigo" tuvo formas de instrumentación diferentes en cada país y ello es una variable a considerar en una evaluación de los caminos buscados por los perseguidos políticos

detalles, también por los acontecimientos del sesenta y ocho aquí en México en los que el presidente Echeverría babia tenido, cuando no, cuando era solo ministro de Gobernación, alguna participación, habia tal vez una, un dejo de culpa, digamos que querria tal vez envanecer, y poner fuera de toda duda que (...) este es un país abierto, limpio, democrático, eso es lo que creo". Entrevista a González Salazar, op. cit.

25. "La participación más relevante del gobierno mexicano en materia de colaboración se originó el viernes 11 de mayo... Abi el presidente Allende me solicitó la ayuda del gobierno mexicano para resolver los problemas que se le habian presentado a Chile por la escasez de gasolina y parafina... El 16 de mayo... tuve la oportunidad de informar al presidente Allende, en presencia del Ministro de Minería Sergio Bitar, que el Venustiano Carranza ya habia zarpado del Golfo de México hacia Valparaíso, y que el Plan de Ayala lo haria de un momento a otro". Martínez Corbalá, op. cit., pp. 83-85.

26. Desde aviones mexicanos enviados especialmente para trasladar a los asilados hasta diferentes medidas concretas que solucionaban, por ejemplo, asuntos laborales y habitacionales. Véase ibid., pp.231 y ss.

27. Aunque, también siendo embajador González Salazar, existen datos de que previo al golpe de estado, en Buenos Aires, se apoyó desde la embajada mexicana la salida de algunos perseguidos sin que estos fueran considerados asilados como se menciona en la nota 21 de este artículo.

28. Martínez Corbalá, op. cit., p. 206.

29. Entrevista realizada a González Salazar, op. cit. 
para sortear el encuentro con las fuerzas represivas. Además la valoración de que el camino es el asilo diplomático, por tanto la salida al exterior con el consecuente sentimiento de abandono que todo exilio conlleva, no es compartida fácilmente por quienes hasta momentos antes estaban en una actividad que trascendía su ámbito personal, o bien no se encontraban involucrados en ninguna actividad política y la persecución era resultado de la vinculación familiar o de amistad. Y también, por último, la información que los propios perseguidos tenían en el momento de decidir qué hacer sobre las posibilidades concretas del asilo. O sea, en Chile se fue haciendo colectiva la información de que un camino era el asilo en tanto varias embajadas, y algunas muy en particular, concedían la protección favoreciendo en esas circunstancias un ánimo colectivo por esa opción de sortear la represión. En cambio, en Argentina la situación fue considerablemente diferente, primero, porque la persecución fue previa al golpe de estado, en medio de la confrontación y allí no estaba planteado desertar y segundo, porque la escasa disposición diplomática a brindar protección, y el control militar riguroso de las mismas, conformó una idea colectiva de que era un camino poco acertado y muy riesgoso.

En suma, lo que incidió al mismo tiempo (e incide en circunstancias similares) fue una serie de variables independientes al estado asilante y al diplomático que lo representaba que coadyuvaron en el tipo, número y tiempos de las solicitudes.

\section{PARA CONCLUIR}

Es cierto que la regulación busca proteger a los perseguidos políticos y para ello estipula los derechos y las obligaciones de los estados que conceden el asilo y los que deben reconocerlo para facilitar la salida de quienes obtienen la calificación de asilados ${ }^{30}$. Con ello se ampara el interés por proteger los derechos humanos y se instrumenta su práctica. La firma y ratificación de los convenios específicos ha representado así la voluntad de los gobiernos por generar políticas de estado que avalen tal legislación.
Toda vez que el asilo diplomático debe ponerse en práctica se hacen evidentes al menos tres niveles de condicionantes. Uno referido a la disposición de un estado de reconocer el asilo y ejercerlo cuando las coyunturas lo requieran. México tiene, en este sentido, una larga trayectoria en su disposición a poner en práctica su política de asilo. Sin embargo, otro nivel vinculado a la política interna del estado asilante condiciona cuáles son los momentos más propicios para abrir las embajadas y cuáles los actores políticos que requieren de urgente y incondicional amparo como se hace evidente en las experiencias ocurridas en Argentina y Chile en los años setenta. El tercer nivel involucra la forma y el momento que cada representante diplomático considera como los más apropiados para conceder el asilo, es decir la decisión diplomática in situ que está, a la vez, estrechamente relacionado con la percepción que, de las crisis políticas, de las rupturas institucionales y de sus repercusiones en tanto violaciones a los derechos humanos en todos los grados, tienen los diplomáticos acreditados en los países en conflicto ${ }^{31}$. Esto último es pues lo que relaciona la valoración de lo que está ocurriendo y la forma de atenderlo desde la política de estado.

Ejemplos de estos niveles de condicionamiento a la regulación del derecho de asilo en situaciones que la historia mostró como equiparables se desprenden de los diferentes documentos que permitieron reconstruir las experiencias de asilo en las representaciones diplomáticas mexicanas en Argentina y Chile. De ahí que cabe ratificar la constatación de que aún falta mucho camino por andar para que la regulación incorpore aspectos que debiliten los condicionantes y con ello favorezcan un mayor equilibrio entre filosofía y aplicación.

30. La Convención de Caracas de 1954 (sobre Asilo Diplomático y Asilo Territorial) avanzaron en términos de derechos y obligaciones de las partes involucradas.

31. Una aproximación para el estudio de este segundo nivel se encuentra en mi trabajo artículo "Crisis políticas y visión de los diplomáticos” en Silvia Dutrénit Bielous y Guadalupe Rodríguez de Ita, op. cit.

\section{RESUMEN}

A lo largo de los años se cuentan por miles los latinoamericanos que recurrieron al asilo como forma de protegerse de la persecución gubernamental. El asilo es un instrumento del derecho interamericano, ratificado como tal por varios estados, para salvaguardar vidas humanas, es decir la de los perseguidos políticos bajo distintos regímenes. La regulación de este instrumento ha sido asunto recurrente de debate y de modificación. En este artículo se presentan hipótesis que problematizan los alcances de la regulación del asilo diplomático y se presentan ciertas claves a partir de condicionantes externas, especialmente en lo que se deline como la percepción y la decisión políticas de los diplomáticos. Para ello se rastrean dos experiencias de los años setenta ocurridas en Argentina y Chile desde un escenario común: las embajadas mexicanas y la disposición estatal de proteger a los perseguidos políticos. Chile.

Palabras clave: Asilo diplomático, golpes de estado, perseguidos políticos, embajadores, México, Argentina y

\section{ABSTRACT}

Historically, thousands of Latin Americans have sought political asylum to shield themselves from government's persecution. Many States in the region have ratified it as a legitimate instrument of Interamerican Law, useful to protect the lives of people being persecuted by their governments due to their political stance. The regulation of this instrument has experienced various modifications, and has been the subject of a recurrent debate. This paper puts forward alternative hypotheses to explain the scope of the regulation of political asylum, and introduces certain codes to understand it based on external conditions, in particular, concerning foreign diplomat's perceptions and political decisions. To do so, we examine two cases that took place in the 1970 in rgentina and Chile from a common perspective: that of Mexican embassies and the State's willingness to protect people subject to political persecution

Key Words: Diplomatic asylum, coups d'etat, political persecution, ambassadors, Mexico, Argentina and Chile. 